\title{
Simultaneously contrasting anchors
}

JOSEPH A. STEGER ${ }^{1}$ AND EDMUND OTEILLY ${ }^{2}$ STATE UNIVERSITY OF NEW YORK AT ALBANY

\begin{abstract}
Subjects were required to judge a series of weights in the presence of two opposing anchor weights, one heavier and one lighter than the series members. It was predicted that the anchors would enhance each other's effectiveness (contrast). The findings are similar to that found for the single-anchor experiment, with the exception that, and contrary to prediction, the heavier-weight anchor reduced the effectiveness of the lighter-weight anchor. The opposite effect was not true. It is suggested that a pair of opposing anchors could be identified that would completely cancel each other's effectiveness.
\end{abstract}

Although much psychophysical research has employed the anchor experiment ${ }^{3}$ (Adamson, 1967; Bevan, 1968; Brown, 1953; Helson, 1964; Sarris, 1967; White, Alter, Snow, \& Thome, 1968), as far as we can ascertain, no one has employed simultaneously contrasting anchors (herein referred to as the mixed-anchor situation) in the same modality. Turner and Bevan (1962) have investigated the role of anchoring for a multidimensional stimulus, namely, form, and have presented such multiple anchors as size and shape or color and shape. However, the impact of these multiple anchors was on the particular dimension of a given anchor. Even though, for example, size and shape anchors were presented simultaneously, they acted independently upon size and shape, respectively. Our concem was with two opposing anchors in the same modality, having an impact upon the same stimulus dimension. We therefore were interested in both methodological and theoretical considerations of this problem.

Methodologically, the question was, very simply, would Ss respond in some systematic way to a given stimulus while two opposing anchors were present? In other words, was the task possible without over-complicated experimental procedures or training?

Theoretically, our interest centered upon the judgmental process and whether or not anchor effects in the mixed-anchor situation would be the same as anchor effects in the single-anchor situation.

From the work of Helson (1964) and others (see, for example, Sarris, 1967; White, Alter, Snow, \& Thorne, 1968), it has been demonstrated that, within given limits, the anchor can serve as the context or frame of reference in which a series of stimuli are judged, and that an anchor above the series is more effective than an anchor below the series. It has also been shown that judgments of series members having a value nearest that of the anchor are more influenced by the anchor than by judgments of series members further from the anchor. Following from these early findings, we would expect that anchors in the mixed-anchor situation would produce these same effects upon the series members as well as having similar effects upon each other. That is, the presence of opposing anchors should increase the impact of each anchor. This would follow from perceptual contrast.

In order to have the weights simultaneously effective, we had Ss lift weights with both hands at the same time. To see if this technique posed any problems, we had Ss lift two anchors of the same weight, one in each hand, and then lift two series members both of equal weight. They were then asked to report one hand's judgment followed by the judgment in the other hand. Surprisingly, this task was quickly adapted to, and the Ss soon realized that both hands were being given the same weights. Thus, to test our expectancies about mixed-anchor effects, we simply had the $S$ judge one series (same weight in each hand) following two different anchors, one in each hand.

\section{Apparatus \\ METHOD}

Two sets of identical weights were constructed for the five series members $(200,250,300,350,400 \mathrm{~g})$ and two anchors $(90,900 \mathrm{~g})$ out of lead shot and glass jars. The only other equipment was a clock (Standard) and a plywood panel through which the $S$ placed his forearms. The panel had built-in padded armrests that allowed the $S$ to comfortably place his arms (palms up) on the rest with his hands free to receive the weights. This provided visual shielding of the stimuli, so at no time did the $S$ see the weights he was to judge. Mounted on the panel facing the $S$ was a 9-point, open-ended scale, going from very, very light to very, very heavy.

\section{Subjects}

Forty college students (aged 17 to 27), all naive with respect to the experimental problem, were randomly divided into two equal groups. Each $\mathbf{S}$ was run under both the same- and mixed-anchor conditions 7 to 14 days apart.

\section{Procedure}

The Ss lifted two anchor weights (one in each hand) simultaneously and then lifted two identical series weights (one in each hand). They were then asked to report their judgments of the second two weights, first one hand (left or right, the first report being assigned randomly) followed by the judgment of the weight in the other hand. In order to facilitate the reporting of the judgments and to avoid confusion about left and right, the $S$ was informed that he should report first the judgment of the hand that the $\mathrm{E}$ touched followed by his judgment of the stimulus in the other hand.

Each $S$ was seated facing a table upon which the panel board and armrests were positioned. The $\mathbf{S}$ was instructed to place both hands through the openings provided and to rest his arms on the armrests with his palms facing up. The $S$ was then read the following instructions.

"This is an experiment in judging weights. You are to judge a series of weights and assign them a value on the scale you see in front of you. I will simultaneously place a weight in each hand (E demonstrated), then take these away and place a second weight in each hand. I will touch the hand that you are to report first. Remember, the judgments of the second set of weights are those that you are to report.

"Do you have any questions?"

After each $\mathbf{S}$ was instructed, he was given two practice sessions and then given five test runs in which his responses were recorded. Throughout the experiment, the presentation of each series-stimulus was determined randomly.

The presentation of time of a given weight was approximately $5 \mathrm{sec}$, and the time between series weight and anchor was 3 sec. The time between successive pairs of stimuli was 2-3 sec each. The entire session lasted about $20-30 \mathrm{~min}$.

\section{RESULTS}

Following from previous research using a single hand and single judgment (Helson, 1964; Bevan, 1968; Sarris, 1968), we also found that, in the situation where both hands were given the same anchor 


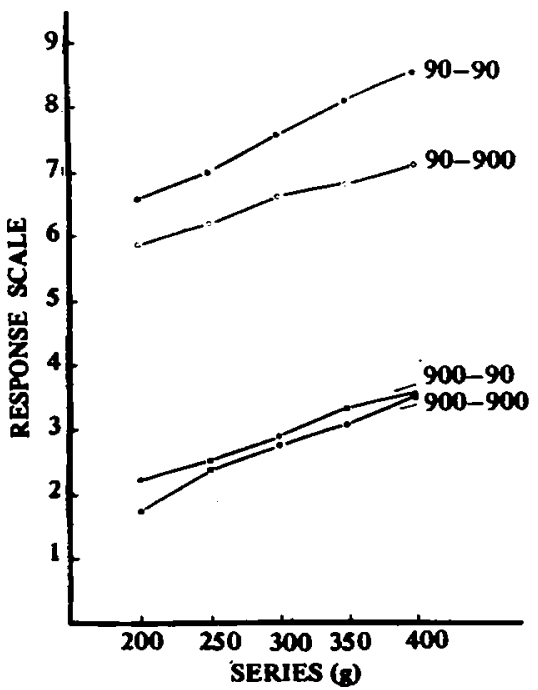

Fig. 1. Mean judgments of series members by anchor condition. In the mixed-anchor situations, $900+90$ and $90+900$, the first numeral designates the anchor under which the series was judged and the second numeral the value of the anchor held in the opposite hand.

$(900+900$ or $90+90)$, the anchors served as reference points, and that the series members were judged accordingly. In Fig. 1, the mean judgments of the series for both hands following two similar anchors are presented for each anchor group. The judgments for both hands (identical series and anchors) were combined and an average was computed, since $t$ tests of the mean judgments for each hand, within each group, were nonsignificant [Group $900+900$, left-hand mean $=2.63$, right-hand mean $=2.73, t(19)=2.07$, p > .05; Group $90+90$, left-hand mean $=$ 7.59 , right-hand mean $=7.58, t=.15$, $\mathrm{p}>.05]$.

It can be seen that the series judged in the presence of the $90-\mathrm{g}$ anchor were identified as heavy and the same series, in the presence of the $900 \mathrm{~g}$ anchor, as light. It is also apparent that the judgments under each anchor condition of each series member fall in the predicted order, that is, the $200-\mathrm{g}$ series member being judged the lightest and then the $250-g$ series member being judged relatively heavier and so on. Thus, the data shown in Fig. 1 establishes that the two groups of Ss performed the same as would be found in the single-hand anchor paradigm experiment.

The results of the mixed-anchor situation are also shown in Fig. 1. Since our concern is within each mixed-anchor condition, we shall discuss these two conditions separately. It can be seen that in the $900-90$ mixed-anchor condition, the presence of the $90-\mathrm{g}$ anchor did not appear to alter, in any reliable way, the judgment of the series under the $900 \mathrm{~g}$ anchor. This is supported by the statistical effects of the anchor conditions, i.e., $900+900$ vs $900+90$ were found to be nonsignificant $[F(1,4)=4.91, p>.05]$; the judgments of series members, however, do differ significantly $[F(4,4)=44.62, p<.01]$. This simply means that each member of the series was judged at a different level of heaviness than were the other members of the series. This is as would be expected and is of no special importance to the current investigation-it follows what is typically found in the anchor type of experiments.

It was also apparent from the statistical analysis that $S s$ under the $900+90$ condition differ significantly $[F(19,171)=3.46, p<.01]$ in their response to the series members. An analy sis of individual $S$ performance showed that some Ss judged everything heavier or lighter than did other Ss, or, in other words, while the relative position of the series members are judged the same, the only difference between $S s$ is one of absolute level of judgment.

In summary, then, the additional anchor of $90 \mathrm{~g}$, in the hand opposite the $900 \mathrm{~g}$ anchor, had no significant effect upon the judgments made of the series members in the hand having received the $900-\mathrm{g}$ anchor.

Retuming to Fig. 1 , it is readily apparent that the $900-\mathrm{g}$ anchor in the hand opposite that holding the $90_{-8}$ anchor did have an effect upon the judgments of the series members under the $90-\mathrm{g}$ anchor. The presence of the $900-\mathrm{g}$ anchor depressed all of the judgments of the series under the $90 \mathrm{~g}$ anchor. In other words, it acted to make all judgments seem lighter, even though the series was still judged on the heavy side of the response scale. The reliability of this effect is attested to by the statistical analysis where the effects of anchor conditions, i.e., $90+90$ vs $90+900$ were found to be statistically significant $[F(1,4)=60.84, p<.01]$.

It can also be seen in Fig. 1 , from a comparison of the $90+90$ and $90+900$ data points, that the $900-\mathrm{g}$ anchor in the mixed condition had a greater effect upon the heavier series members. This effect was also statistically significant [series by anchor condition, $F(4,171)=4.32$, $\mathrm{p}<.01]$.

As was found in the $900+90$ condition, both series $[F(4,4)=90.25, p<.01]$ and Ss $[F(19,171)=6.20, p<.01]$ produced significant effects. These are to be explained in the same way they were for the $900+90$ condition.

In summary, under the $90+900$ condition, it was demonstrated that the $900-\mathrm{g}$ anchor did have a significant effect upon the judgments of the series members under the $90-\mathrm{g}$ anchor. Thus, simultaneous anchor effects in the same dimension have been demonstrated.

\section{DISCUSSION}

This experiment has demonstrated that Ss can make ratings in the presence of simultancously contrasting anchors, and that these ratings are reliable. It has also been demonstrated that anchor scting simultaneously can influence the judgments of series members of their own series and of series members judged under the other anchor. Thus, the role of multiple adaptation levels and their possible interactions becomes of importance.

Our data showed that the $900-8$ anchor acted to reduce the effectiveness of the 90-g anchor when both were presented simultaneously; on the other hand, the 90-g anchor had little, if any, impact on the judgments under the 900-g anchor. This suggests that our selection of anchors was not optimal in that they did not have equal effectiveness. Future research needs to establish the relation of anchor effectiveness in terms of adaptation levels or frames of reference. The need for a more specific quantitative formulation that can incorporate simultaneously active adaptation levels is also apparent. Certainly, judgments are very rarely made with a single normative or adaptive level operative.

We stated in the introduction that we expected the anchors to produce psychological contrast in relation to each other. Therefore, the effect of the anchor on a series member should be greatest when in the presence of a second anchor. We found, however, that in the mixed-anchor situation, the effectiveness of the anchor is reduced. This appears to be because the series members were judged relative to the anchors, and contrast occurred between each anchor and the series. Hence, one anchor is raiking the judgment, while the second is lowering the judgment, and they tend to cancel each other's effectiveness. We should then be able to select two different anchors, one above and one below the series that would yield a judgment of the series that would be equivalent to judgment of the series alone.

Psychology has available many models of the relationship between stimuli and the judgments of these stimuli (e.g., see Anderson, 1967; Anderson \& Jacobson, 1968; Helson, 1964; Parducci, 1963, 1965; Sarris, 1967; Sherif \& Hovland, 1961; Stevens, 1957, 1966). Our contention is, however, that until these models are tested under conditions of multiple anchoring. 
their theoretical generality and everyday applicability are extremely limited.

\section{REFERENCES}

A.DAMSON, $R$. Anchor effect limits. Psychonomic Science, 1967, 9, 179-180.

ANDERSON, N. H. Application of a weighted average model to a psychophysical averaging task. Psychonomic Science, 1967, 8, 227-228.

ANDERSON, N. H., \& JACOBSON, A. Further dat on a weighted avernge model for judgment in a bifted weight tusk. Perception \& Psychophysics, 1968, 4, 81-84.

BEVAN, $\mathbf{w}$. The contextual basis of behavior. American Psychologist, 1968, 23, 701-714.

BROWN, D. R. Stimuluserimilarity and the anchoting of subjective scales. American Journal of Psychology, 1953, 66, 199-214.

HELSON, H. Adeptation-level theary. New York: Happer \& Row, 1964.

PARDUCCI, A. Category judgment: A range-frequency model. Psychological Review, $1965,72,407-418$.
PARDUCCI, A. Range-frequency compromise in judgment Psychological Monographs, 1963, 77 , No. 565 .

SARRIS, V. Adaptation level theory: Two critical experiments on Helson's weighted average model. American Journal of Psychology, 1967, 80, 331-344.

SHERIF, M., \& HOVLAND, C. J. Social judgment. New Haven: Yale University Press, 1961.

STEVENS, S. S. On the operation known as judgment. American Scientist, 1966, 54, $385-401$.

STEVENS, S. S. On the psychophysical law. Psychological Review, 1957, 64, 153-181.

TURNER, E. D., \& BEVAN, w. Simultaneous induction of multiple anchor effects in the judgment of form. Journal of Experimental Psychology, 1962, 64, 589592.

WHITE, B. J., ALTER, R. D., SNOW, M. E., \& THORNE, D. E. Use of instructions and hypnosis to minimize anchor effects. Joumal of Experimental Psychology, 1968, 77, 415-421.

\section{NOTES}

1. Address: State University of New York at Albany, 1400 Washington Avenue, Albany, New York 12203.

2. Now at Bard College, Annandale-on-Hudson, New York.

3. The anchor experiment is here defined as one in which a $S$ receivos a given stimulus (anchor), followed by the second stimulus (eries member) which is to be judged. This differs from the psychophysical method of standard and varinble in that the $S$ is told to ignore the first member of the puir and to judse only the second stimulus He is never told to judge the second stimuhus relative to the first.

(Accepted for publication August 6, 1969.) 